\title{
PEDAGOGY, MEDICAL EDUCATION AND CINEMA: A POSSIBLE ENCOUNTER
}

\author{
Pedagogía, educación médica y cine: un encuentro posible \\ Carlo OREFICE \\ e-mail: carlo.orefice@unisi.it \\ Department of Education, Humanities and Intercultural Communication. University of Siena (Italy).
}

Fecha de recepción: 10 de octubre de 2019

Fecha de aceptación: 23 de octubre de 2019

Fecha de publicación: 15 de septiembre de 2020

Why write about the Journal of Medicine and Movies?

My relationship with the Journal of Medicine and Movies (JMM) and its Publishers started in 2013. In June of the same year, as a young researcher of Pedagogy at the Faculty of Medicine at the University of Florence, I made a stay at the Department of Preventive Medicine, Public Health and Medical Microbiology of the Faculty of Medicine at the University of Salamanca (Spain).

Many goals brought me to that country which over time has become a sort of «second home» for me, from an emotional and professional perspective.
In fact, as a researcher, I was interested in exploring some socio-pedagogical models of comparative evaluation of film languages and learning technologies that I had begun to use, and in investigating theories and methods of medical anthropology (subsequently, in 2014/2015, I went to the Medical Anthropology Research Center in Tarragona and, on several occasions, to the Faculty of Health and Life Sciences of the Pompeu Fabra University in Barcelona).

Thus, in my initial academic career, the University of Salamanca, and subsequently the JMM, turned out to be a physical place and a conceptual tool, through which start to (re)think 
the medical education and its relation-ship with Medical Humanities, as well as cinema (and the audiovisual sector) as a training tool.

The relationship between JMM and the Film Archive for medical education

In defining the motivations and objectives of this report, an effective link between my academic career and the JMM was found through the development of a Film Archive for medical education, an instrument that I designed in 2012, which has been useful to support university teaching at the Faculty of Medicine (University of Florence).

The Archive, which was online since 1 March 2012, was in fact a technological product of the "Laboratory of Medical Education» of the School of Human Health Sciences where I used to work.

Using a scientific methodology, the Archive collected and ordered short video sequences (such as movie scenes) taken from different types of audiovisual product (film, documentary, student drawings, TV series). These sequences were chosen and systematically merged in relation to specific topics (key words), selected through a peer-to-peer work (which involved students and other teachers) considering the priority of topics in the field of training of care professionals (professional fields) ${ }^{1}$.

This is how the JMM and the Archive, became a useful tool through which the cinematographic practice and the medical training found their mutual recognition.

\section{Share information and define new meanings}

Presenting a series of information in a multimodal form (i.e. through images, texts, videos, and sounds), the Archive made it clear that the human mechanism of perception/cognition was closely linked to the complexity of the elements that are subjective, corporeal, experiential, mnemonic and sensorial. Therefore, the Archive represented not a simple tool for gathering different types of films, nor a further guide to underline the relationships between cinema and medical education, but a specific "platform» that allowed participants in training to interpret significant information, that helped them to reflect on their own experiences and their own meaning, to emphasize the cognitive relationships that, as individuals, can be used with others, and to identify the "social» characteristics of knowledge and learning.

At this purpose the JMM, during these years, has shown - in my opinion - that using cinema in training means recognizing learning as a process related to the tools that can be used to solve a certain problem, this aspect is founded on the construction of knowledge and not on its passive transmission and reproduction. Moreover, the JMM, over the course of all these years, has been useful to appreciate the open access to the Magazine and the plurality of idioms (English, Spanish) through which the various Authors can present their contributions.

From this perspective, the networking of the JMM and its Publishers has always seemed precious to me, considering that it was (and it is) carried on by a Faculty of medical sciences which generates (both in Spain and in Italy) ${ }^{2}$ its knowledge starting from the biomedical paradigm, focused on models of diseases and symptoms that often may appear "not so open» to other scientific paradigms.

Furthermore, the cinema, and its broader meaning and use, provided to several professionals another knowledge pespective, which is connected to the emotions, highlighting how the «illness" and the "wellbeing" are objects of interpretation, i.e. are constructs of the social and personal imagination of individuals ${ }^{3}$.

\section{Building networks of professionals on common issues}

The JMM provided, over the years, a series of information, good practices, case studies, theoretical reflections on the relationship between 
cinema and medicine, and it has succeeded in making different points of view among the Authors who wrote a «critical-reflective» thought about this topic.

This request coincides with the need to clarify our systems of beliefs, objectives and intentional states in order to make the world we live as a constant opportunities to discover new meanings. This aspect is linked to the idea that the "effectiveness» of training does not lie in the measurability and verifiability of learning, but in the ability that has this latter to promote the processes of reinterpretation and recomposition of what has been learned before ${ }^{4}$.

Learning, in short, can be considered as a process and not as a product, and the Editors of the Journal have reminded us this aspect with tenacity over the years.

I believe that we can reasonably argue that the JMM is configured as a space of interaction and communication and as a sort of «device» (in this case online) through which is possible to share intelligence and knowledge with other Authors, in order to collaborate and learn - through cinema - the common priority issues / problems for the professionals involved.

This peculiarity of the JMM and its ability in facilitating the establishment of a "community of practices» appears particularly significant to me and makes this Journal a useful instrument able to make available several experiences to verify references, conditionings, parallels or divergences about the binomial health / disease.

\section{Future perspectives and new training oppor- tunities}

This synthetic reconstruction of my professional and personal journey, based on cognitive explorations and geographic journeys, underlined - in my opinion - the innovative opportunity promoted by the JMM for health professionals to build collaborative construction of knowledge, as well as to (re)think about medical education and its relationship with Medical Humanities ${ }^{5}$.

It is clear that the JMM in its constant work of diffusion and reflection carried out over the past 15 years, has promoted the establishment of international networking, favoring both the overcoming of rigid disciplinary approaches (which are often closure to the interdi- sciplinary dialogue and hyper-specialization) that the verification and validation of "other" training models, through which think about the professional skills. In doing so, the JMM urged us to consider cinema as an opportunity to intervene on learning, that call us into question as university professors.

I hope that these paths can continue to be explored and investigated in the future, also thanks to the JMM.

\section{References}

1. Orefice C. Guidelines for an "Operative Constructivism» in the learning process through Cinema. The Film Archive for Medical Education of the University of Florence. Rev Med Cine 2014; 10(3): 127-32.

2. Orefice C, Pérez J, Baños J-E. The presence of humanities in the curricula of medical students in Italy and Spain. Educ Med. 2019; 20(S1): 79-86.

3. Orefice $C$. Costruire la consapevolezza dei modi di "stare al mondo». In: de Mennato P, Orefice C, Branchi $S$, editors. Educarsi alla «cura». Un itinerario riflessivo tra frammenti e sequenze. Lecce: Pensa MultiMedia; 2011. p. 123-76.

4. Orefice C. Relazioni pedagogiche. Materiali di ricerca e formazione. Firenze: Firenze University Press; 2013.

5. Orefice $C$, Baños JE editors. The role of humanities in the teaching of medical students. Barcelona: Dr. Antoni Esteve Foundation; 2018. 


Carlo Orefice is Associate Professor of General and Social Pedagogy at
the University of Siena. His main research interests are focused on adult
education, specifically on learning processes and the creation of knowledge
referred to the cultural field. At the national and international level, he
has carried out teaching, research and intervention activities with several
institutions and he currently participates in interuniversity projects. Since
2017 he is Chair Adjunct Professor at the "UNESCO Transdisciplinary Chair
in Human Development and Culture of Peace» (University of Florence).

